\title{
Optimization of bioethanol production process using oil palm frond juice as substrate
}

\author{
Maya Emira Mad Saad, Abdul Halim Farah Amani and Lee Chee Keong* \\ Bioprocess Technology Division, School of Industrial Technology, Universiti Sains Malaysia, 11800 USM Penang, \\ Malaysia \\ Email: cklee1311@yahoo.co.uk
}

Received 8 March 2016; Received in revised form 18 July 2016; Accepted 21 July 2016

\begin{abstract}
Aims: Bioethanol is an environmental friendly energy source with a lot of great prospective and become an alternative to fossil fuels .Oil palm frond juice (OPFJ) is a potential sources of sugars for bioethanol production. The present study aimed to optimize bioethanol production.

Methodology and results: Bioethanol fermentation was carried out by Saccharomyces cerevisiae HC10 using OPFJ as substrate in bioreactor with $1.5 \mathrm{~L}$ working volume. Growth profile was performed for $42 \mathrm{~h}$ with sampling every $3 \mathrm{~h}$ interval. Effect of agitation speed (rpm) and volume of OPFJ were screened to select significant factor for high production of bioethanol. Agitation speed at $175 \mathrm{rpm}$ and volume of oil OPFJ; $40 \%$ gave $5.25 \mathrm{~g} / \mathrm{L}$ and $4.52 \mathrm{~g} / \mathrm{L}$ of ethanol and biomass concentration, respectively. These parameters were further investigated via central composite design (CCD) of Response Surface Methodology (RSM) to maximize bioethanol production. The suggested optimum conditions for bioethanol production were agitation speed at $152 \mathrm{rpm}$ and volume of OPFJ at $39.71 \%$ in which giving ethanol concentration of $4.79 \mathrm{~g} / \mathrm{L}$. Growth profile after optimization indicated that the highest ethanol concentration (5.75\%) was achieved after $15 \mathrm{~h}$ of fermentation. Kinetic studies indicated that ethanol yield coefficient $\left(\mathrm{Y}_{\mathrm{p} / \mathrm{s}}\right)$ due to consumption of OPFJ and productivity of ethanol was 3.5 fold and $25 \%$ increased compared to before optimization, respectively. While, in term of ethanol yield about $9 \%$ increased was observed.

Conclusion, Significance and Impact of study: This showed that OPFJ can be an alternative new feedstock for bioethanol production using S. cerevisiae $\mathrm{HC} 10$.
\end{abstract}

Keywords: Oil palm frond juice, Saccharomyces cerevisiae HC10, bioethanol, response surface methodology, optimization

\section{INTRODUCTION}

Brazil and USA are the first bioethanol producers with the world production about 51 million liters with an average of $73 \%$ of produces ethanol worldwide, $17 \%$ to alcoholic beverage and $10 \%$ to industrial ethanol (Niga, 2009). Bioethanol can be a product from an edible source which known as first generation bioethanol such as sugarcane and corns. Second generation of bio-ethanol is from lignocelluloses biomass is from non-edible source such as palm oil biomass. This make second generation of bioethanol is a better choice to replace fossil fuel without disturbing food sources. By converting the waste into valuable product, it can reduce the environmental problem. Lignocelluloses material contain about 50\% $60 \%$ carbohydrate in the form of cellulose and hemicelluloses which may be fermented to ethanol and $20 \%-35 \%$ of lignin content (Galbe and Zacchi, 2007). Nowadays, oil palm tree is one of the main source for the production of bioethanol but there are not much attention is been given to oil palm sap which are product that come from the tree component such as oil palm trunk and oil palm fronds.

Malaysia is one of the largest exporters of palm oil product in the world. Malaysia produces a large amount of agro-industrial residue with oil palm industry itself produced about 83 million tons of residues in 2012 (Rozario, 2013). Malaysia has produced about 62.25 million tons of oil palm trunks and oil palm fronds of the total palm biomass in year 2012 and increasing of oil palm biomass in Malaysia is predicted to be 100 to 110 million tonnes by year 2020 (Rozario, 2013). Biofuel that produces from oil palm tree is an environmental friendly and low cost therefore many interests are being shown to these sources. Mostly, the major parts of the solid biomass from the oil palm tree are being leave behind on the plantation is to be found as oil palm fronds (Zahari et al., 2012).

Oil palm frond is one of the useful raw materials for the production of bioethanol which is environmental friendly 
way. Pre-treatment of the oil palm fronds need to be done to achieve good bioethanol production. However, pretreatment step for the bioethanol production from lignocellulosic biomass is relatively expensive. The main contradict are low yield and cost of the hydrolysis process (Sun and Cheng, 2002).

Thus, oil palm frond juice (OPFJ) is being introduced as another source for the production of bioethanol. Previous study has been shown that oil palm frond juice is suitable to be used as fermentation feedstock because there was no inhibition on microbial growth or product formation, there were no impurities, it was easy to be operated, and it had no risk on health and safety (Zahari et al., 2012). Oil palm frond sap has been proved by Lee and Halim (2014) contains high sugar content which is $77.69 \%$ from total free sugar content. In Malaysia, a study shows that glucose is the dominant sugar in the oil palm sap (Kosugi et al., 2010). Since there are many studies show that oil palm frond juice contains higher sugar content, a higher level of production of bioethanol from oil palm sap is possible.

A study by Nwachukwu et al. (2008) shows that improving yeast resistance by protoplast fusion increased yields of ethanol by $16 \% \mathrm{v} / \mathrm{v}$. Apart from that, fermentation technologies also help to improve the production of bioethanol. There are three types of fermentation that can increase the production of bioethanol which are batch, fed-batch and continuous fermentation. This project aim is to increase the yield of the bioethanol production using oil palm frond juice as feedstock via batch fermentation process.

\section{MATERIALS AND METHODS}

\section{Oil palm frond juice (OPFJ) preparation}

Oil palm fronds were obtained from local plantation plant located at Balik Pulau, Penang, Malaysia. All the leaves and outer layer of OPF were removed to get the smooth layer of OPF and were pressed using sugarcane machine press as soon as possible to avoid moisture losses (Zahari et al., 2012) and also fungus grow. OPFJ obtained were centrifuged at $10,000 \mathrm{rpm}$ for $15 \mathrm{~min}$ and a clear yellowish supernatant color was obtained (Lee and Halim, 2014). To avoid sugars degradation, the OPFJ were stored in freezer at $-20^{\circ} \mathrm{C}$ (Dinie et al., 2014) prior to use.

\section{OPFJ sugar composition analysis}

Fructose, glucose and sucrose were determined using High Performance Liquid Chromatography (Shidmadzu, Japan) equipped with refractive index (RI) using ApsHypersil column with diameter of $250 \mathrm{~mm} \times 46 \mathrm{~mm}$ (Lee and Halim, 2014). Mobile phase used was $85 \%$ of Acetonitrile and $15 \%$ de-ionised water. The flow rate and oven temperature used were $0.6 \mathrm{~mL} / \mathrm{min}$ and $40^{\circ} \mathrm{C}$, respectively.

\section{Preparation of S. cerevisiae HC10 strain}

One hundred $\mathrm{mL}$ nutrient broth medium (yeast extract, 5 $\mathrm{g} / \mathrm{L}$; peptone, $10 \mathrm{~g} / \mathrm{L}$; and $15 \%$ of glucose solution, $50 \mathrm{~g} / \mathrm{L}$ ) (Farhana and Jamaludin, 2010) were prepared in a 250 $\mathrm{mL}$ conical flask. Glucose solution nutrient broth was autoclaved separately at $121^{\circ} \mathrm{C}$ for $15 \mathrm{~min}$. Stock culture of $S$. cerevisiae $\mathrm{HC10}$ were sub-cultured into the conical flask contained nutrient broth media and was incubated for $24 \mathrm{~h}$ at $150 \mathrm{rpm}$ and $30{ }^{\circ} \mathrm{C}$. Nutrient agar slant were prepared in universal bottle using the same media composition mentioned above with the addition of $20 \mathrm{~g} / \mathrm{L}$ of agar powder (Farhana and Jamaludin, 2010). After $24 \mathrm{~h}$ incubation, culture was streaked onto the agar slant and was incubated for 3 days at $30^{\circ} \mathrm{C}$. Grown colonies on the agar slant were stored in refrigerator at $4{ }^{\circ} \mathrm{C}$ for further use.

\section{Substrate sterilization and inoculation}

OPFJ was transferred into bioreactor and autoclaved at $121^{\circ} \mathrm{C}$ for $15 \mathrm{~min}$. The sample was allowed to cool down to room temperature before inoculation was carried out under sterile condition.

\section{Growth profile of S. cerevisiae $\mathrm{HC} 10$}

Growth profile was conducted using $2.0 \mathrm{~L}$ bench- top minifors bioreactor (Infors, Germany) with working volume of $1.5 \mathrm{~L}$. Sterilized nutrient broth media was inoculated with $15 \%(\mathrm{v} / \mathrm{v})$ of inoculum and the process was conducted under the optimized condition of $\mathrm{pH} ; 4.5$, temperature; $30{ }^{\circ} \mathrm{C}$, flow rate; 1 volume versus mass (vvm) and $30 \%$ initial oxygen concentration (Lee and Halim, 2014). Fermentation process was carried out for $42 \mathrm{~h}$ and $15 \mathrm{~mL}$ of sample was taken out for every $3 \mathrm{~h}$ interval. Harvested samples were analysed for biomass, sugar and ethanol concentration.

\section{Screening of factors affects bioethanol production}

Effect of agitation and volume of OPFJ was studied in order to know the best condition for maximum ethanol production. For agitation, the factor levels were 100 to 200 rpm with $25 \mathrm{rpm}$ interval. While for the effect of OPFJ volume, the factor levels used were 30, 35, 40, 45 and $50 \%$. The specified parameter were varies by keeping all the other parameters constant. The determined parameter ranges were used in next step of studies.

\section{Optimization of bioethanol production via batch fermentation process}

Optimization of bioethanol production was investigated using CCD of RSM. The experiment was conducted using same bioreactor system with $1.5 \mathrm{~L}$ of working volume for each runs. Thirteen combinations of experimental runs were performed using volume of OPFJ (\%) and agitation speed (rpm) as variables parameters to be studies. The experimental runs were performed according to the 
Design Expert Version 7.0.b1.1 software. After the process was completed, the sample was collected and stored at $-20{ }^{\circ} \mathrm{C}$ for further analysis of biomass, sugar utilization and ethanol production.

\section{Determination of biomass}

The analysis was determined by measuring dry cell weight. Around $10 \mathrm{~mL}$ of cell suspension were vacuumfiltered through $0.45 \mu \mathrm{m}$ filter paper. Cells suspension for each sample was rinsed $2 x$ with distilled water. Filter papers were dried at $70{ }^{\circ} \mathrm{C}$ in an oven for at least $24 \mathrm{~h}$ until constant weighed was achieved. The dried filter papers were weighed on analytical balance to determine the biomass

\section{Residual sugar determination using HPLC system}

All remaining sugar leaved after fermentation was determined according to the method described in OPFJ Sugar Composition Analysis.

\section{Determination of ethanol concentration using gas chromatography}

Ethanol content (\%) in the samples were analysed using Gas Chromatography (GC) (Shimadzu, Japan) equipped with Flame lonization Detector (FID) detector using RT-QBOND column (inner diameter of $0.32 \mathrm{~mm}$ ). The total flow rate was $21.9 \mathrm{~mL} / \mathrm{min}$ and the operating pressure was $71.1 \mathrm{kPa}$. The carrier gas used was Helium $(\mathrm{He})$ and column oven temperature was set at $200{ }^{\circ} \mathrm{C}$ with the holding time for each sample was $5 \mathrm{~min}$.

\section{RESULTS AND DISCUSSION}

\section{Oil palm frond juice sugars composition}

Only three types of fermentable sugar were investigated in the pressed OPFJ, namely glucose, fructose and sucrose. These sugars were utilized by yeast for the production of bioethanol. From the total free sugar obtained, glucose was found to be the major component $(72.58 \%)$. Other sugars present were sucrose accounting for $20.27 \%$ and fructose, $7.15 \%$. This result showed was in agreement with the findings reported by Murata et al. (2013) and Kosugi et al. (2010) who suggested that glucose were the dominant sugar and followed by sucrose and fructose.

The percentage of sugar composition recorded were lower compared to the findings reported by Lee and Halim (2014). In addition, the percentage of glucose was $5.38 \%$ lower but sucrose and fructose showed $4.05 \%$ and $1.33 \%$ higher, respectively. The total amount of free sugar present in OPFJ indicated that OPF contain beneficial sources of carbohydrates that help in bacterial growth. The lower sugar obtained from this studies may due to several factors. One of the reasons may due to less efficient of using sugarcane press machine to press the OPF. A study conducted by Che Mohd Hakiman et al.
(2014) showed that sugarcane pressing machine gave only $47.8 \%$ sugar recovery from total free sugar whereas $88 \%$ of sugar was recovered by hydraulic pressing machine. Other than that, storage of oil palm frond at ambient condition may cause free sugar degradation by microorganisms (Che Mohd Hakiman et al., 2014). The aged of the OPF harvested also one of the crucial factor that affect the sugar recovery where young trees gave more sugars compared to older trees (Murai and Kondo, 2010).

\section{Growth profile of $S$. cerevisiae $\mathrm{HC} 10$ and sugars utilization pattern before optimization}

It can be seen from Figure 1; lag phase was not showed in the growth profile because yeast already adapted during the inoculum preparation. It is essence that inoculum in shake flask gives the better quality of seed culture to be inoculated in the larger scale bioreactor. In the first $9 \mathrm{~h}$ of the fermentation, there was a drastic increased in cell biomass during exponential phase as shown in Figure 1. Deceleration phase was detected between 9 to $12 \mathrm{~h}$ of fermentation. The growth begins to decline after $12 \mathrm{~h}$ and ascend back at $27 \mathrm{~h}$. This occurrence showed the pattern of diauxic growth which happened when the glucose become substrate limiting factor and during this time, there were short lag phase which enzyme were produced by cells to consume another carbon source or nutrient (Shankar, 2013). In the fermentation, ethanol and other products were produced, thus cells utilized this sources to support the growth. On the other hand, stationary phase were observed as there were slow down of growth rate after $30 \mathrm{~h}$ of fermentation.

On top of that, the concentrations of all fermentable sugars were decreased rapidly with an increasing of production ethanol and cell biomass (Figure 1). The sugars were rapidly consumed by cells during exponential phase for growth. The increasing of glucose and fructose indicated that sucrose was hydrolysed into its monomer which composed of glucose and fructose (Shahirah et al., 2014). During the first $3 \mathrm{~h}$ slightly increased in fructose while sucrose were slightly decreased but as for glucose there were no increasing occurred since the cells were intensively consumed by $S$. cerevisiae $\mathrm{HC} 10$ for the growth.

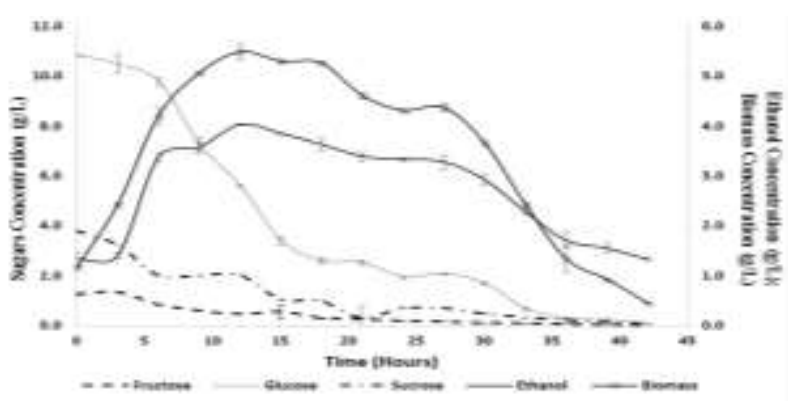

Figure 1: Growth profile of $S$. cerevisiae $\mathrm{HC} 10$ and sugars utilization pattern before optimization. 
In term of ethanol production, the concentration was increasing rapidly at the first $10 \mathrm{~h}$ and reaching maximum concentration of $4.03 \mathrm{~g} / \mathrm{L}$ after $12 \mathrm{~h}$ of fermentation. But the concentration was started to decrease after $15 \mathrm{~h}$. This is because the total sugar concentration became substrate limiting factor in the system and the higher ethanol concentration gave inhibitory effect to the system itself. Apart from that, reduction in ethanol concentration may due to evaporation of ethanol from time to time during fermentation (Shahirah et al., 2014).

\section{Screening of factors affects bioethanol production}

\section{Effect of agitation speed on the growth and ethano} production by S. cerevisiae HC10

Agitation plays an important role in improving the oxygen transfer rate which is beneficial for growth performance. Apart from that, agitation also resulted in better mixing which help for maintaining the homogeneity in bioreactor. This is because better diffusion between exterior and interior gradient of cells help in maintaining good sugar supply and other nutrients to the cells (Rodmui et al., 2008).

The highest ethanol concentration of $5.01 \mathrm{~g} / \mathrm{L}$ and cell biomass of $5.73 \mathrm{~g} / \mathrm{L}$ were achieved with agitation of 175 rpm. Figure 2 proved that growth of $S$. cerevisiae HC10 increased with the increasing in agitation speed from 100 $\mathrm{rpm}$ to $175 \mathrm{rpm}$. At $200 \mathrm{rpm}$ the productivity of ethanol and cell biomass was lower than $175 \mathrm{rpm}$. This means that higher agitation speed will supply more dissolved oxygen to the cultures and allow the cells to carry out aerobic fermentation and become larger cells but too high agitation speed may detrimental to the cells because it will damage or even rupture the microbial cells upon agitation. This current finding were in agreement with a study carried out by Chauhan et al. (2013) who suggested that increased in agitation rate resulted in decreasing of dextransucrase activity.

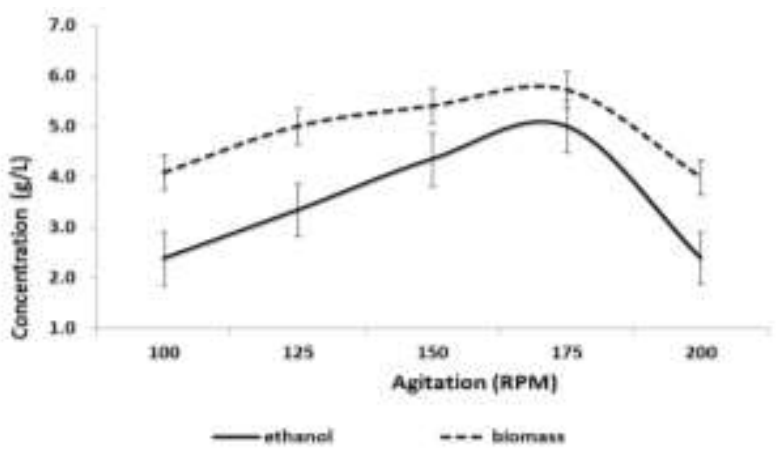

Figure 2: Effect of agitation speed on ethanol production.

Effect of volume of oil palm frond juice (OPFJ) on the growth and ethanol production by S. cerevisiae HC10

Volume of OPFJ used in fermentation for ethanol production is crucial. This is because OPFJ contain fermentable sugars; glucose, fructose and sucrose that help as a carbon sources in fermentation process. $S$. cerevisiae $\mathrm{HC} 10$ utilized these sugars for the growth performance and ethanol production. Increasing the volume of OPFJ in fermentation media will eventually increase the concentration of fermentable sugar until a certain level.

As shown in Figure 3, maximum ethanol production was $4.52 \mathrm{~g} / \mathrm{L}$ with the highest biomass concentration of $5.25 \mathrm{~g} / \mathrm{L}$. This was achieved when $40 \%$ of OPFJ was used in the fermentation media. While, $30 \%$ and $35 \%$ of OPFJ only produced $2.83 \mathrm{~g} / \mathrm{L}$ and $3.48 \mathrm{~g} / \mathrm{L}$ of ethanol, respectively. The results indicated that increasing the volume of OPFJ will increase the biomass and ethanol production. However, further increased of OPFJ volume $(>40 \%)$ in fermentation media resultant decreased in both biomass and ethanol concentration. This phenomenon occurred because yeast cells were exposed to the osmotic stresses which not favour yeast growth and ethanol production (Safri et al., 2011). Efficiency of yeast population decreased when high volume of OPFJ was used in the early fermentation. Thus, it affects the biomass and ethanol production. Study conducted by Maurice (2011) stated that a lower substrate concentration (40 g/L) gave an ideal fermentation condition than high substrate concentration $(80 \mathrm{~g} / \mathrm{L}$ and $100 \mathrm{~g} / \mathrm{L})$ with maximum ethanol yield of $76.28 \%$.

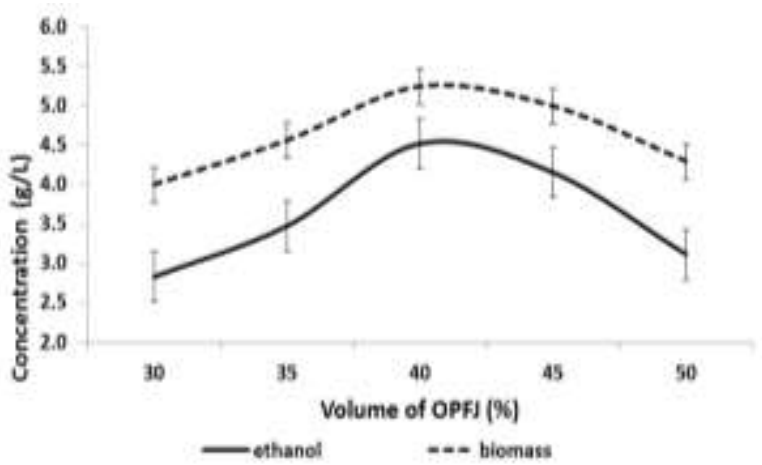

Figure 3: Effect of volume of OPFJ (\%) on ethanol production.

Optimization of batch fermentation process for bioethanol production

Production of bioethanol by $S$. cerevisiae $\mathrm{HC} 10$ was optimized using CCD of RSM. To determine the potential of ethanol yield, 13 experiments were run conducted using Design Expert software version 7.0.b1.1. The Fit summary analysis shows that the suggested model was quadratic with very low probability $p$-value of $<0.0001$ and F-value of 178.13 (Table 1). In Model Summary Statistic, the quadratic model has low standard deviation (0.21) and is acceptable. The R-squared value of 0.9809 means that the fit interpreted $98.09 \%$ of the total variation in the data (Table 2). 
Table 1: Fit Summary Analysis (Sequential Model Sum of Squares [Type I]).

\begin{tabular}{cccccc}
\hline Source & $\begin{array}{c}\text { Sum of } \\
\text { Square }\end{array}$ & df & $\begin{array}{c}\text { Mean } \\
\text { square }\end{array}$ & $\begin{array}{c}\text { F- } \\
\text { Value }\end{array}$ & $\begin{array}{c}p \text {-value } \\
\text { Prob }>F\end{array}$ \\
\hline Mean & 149.72 & 1 & 149.72 & & \\
Linear & 0.11 & 2 & 0.053 & 0.033 & 0.9677 \\
2FI & 0.043 & 1 & 0.043 & 0.024 & 0.8806 \\
Quadratic & 15.83 & 2 & 7.91 & 178.13 & $<0.0001$ \\
Cubic & 0.075 & 2 & 0.038 & 0.80 & 0.5012 \\
Residual & 0.24 & 5 & 0.047 & & \\
Total & 166.01 & 13 & 12.77 & & \\
\hline
\end{tabular}

Table 2: Fit Summary Analysis (Model Summary Statistics).

\begin{tabular}{|c|c|c|c|c|c|}
\hline Source & $\begin{array}{l}\text { Std. } \\
\text { Dev }\end{array}$ & $\begin{array}{l}\text { R- } \\
\text { Squared }\end{array}$ & $\begin{array}{l}\text { Adj R- } \\
\text { Squared }\end{array}$ & $\begin{array}{l}\text { Pred R- } \\
\text { Squared }\end{array}$ & PRESS \\
\hline Linear & 1.27 & 0.0065 & -0.1921 & -0.5700 & 25.58 \\
\hline $2 \mathrm{FI}$ & 1.34 & 0.0092 & -0.3211 & -1.4237 & 39.48 \\
\hline Quadratic & 0.21 & 0.9809 & 0.9673 & 0.8905 & 1.78 \\
\hline Cubic & 0.22 & 0.9855 & 0.9652 & 0.3688 & 10.28 \\
\hline
\end{tabular}

ANOVA report in Table 3 showed the response surface quadratic model with F-value of 71.93 . Low probability $p$ value of $<0.0001$ indicated that the model is significant. The coefficient of $R^{2}$ and $R^{2}$ adj are used to measure the reliability of the model. The value of $R^{2}$ and $R_{\text {adj }}^{2}$ obtained were 0.9809 and 0.9673 , respectively which indicated the model is fit. This show that $98.09 \%$ implies high significance of the model and only $1.91 \%$ from total variations cannot be explained by the model. Values of 'Prob $>F$ ' less than 0.05 indicated model terms are significant. In this case $\mathrm{A}^{2}, \mathrm{~B}^{2}$ are significant model terms with Prob $>F$ value of $<0.0001$. Value greater than 0.10 indicated the model terms are not significant. If there are many insignificant model terms, model reduction may improve the model. The "Lack-of-Fit F-value" of 4.04 implies the Lack-of-Fit is not significant relative to the pure error. There is $10.54 \%$ chance that the "Lack-of-Fit Fvalue" this large occur are due to noise. Non-significant lack of fit is good because we want the model to fit. The "Pred R-Squared" of 0.8905 was in reasonable agreement with the "Adj R-Squared" of 0.9673 . "Adeq Precision" measured the signal to noise ratio. A ratio greater than 4 is desirable. The ratio of 16.824 indicates an adequate signal. Thus, this model can used to navigate the design space.

\section{Verification experiment}

To determine the optimum value of ethanol production, optimization process was accomplished using the DesignExpert Version 7.0.b1.1 software. The agitation and volume of OPFJ were chosen "within" the range to achieve the highest performance result. The only response is ethanol production $(\mathrm{g} / \mathrm{L})$, which was set to be maximum. The optimum conditions suggested by the software were agitation speed of $152 \mathrm{rpm}$ and volume of OPFJ $39.72 \%$. The highest ethanol production (4.79 g/L) was chosen due to the highest desirability of 0.92 for this optimum condition. To verify the predicted result, experiment was conducted using the suggested optimum condition. The experimental value obtained was $4.51 \mathrm{~g} / \mathrm{L}$ which is in agreement with the predicted value of $5.8 \%$ different compare to the predicted value. The percentage error value was calculated from the validation experiment which proved that the optimization process by CCD was dependable and capable for ethanol production from OPFJ using S. cerevisiae HC10.

\section{Growth profile of $S$. cerevisiae $\mathrm{HC} 10$ and sugars utilization pattern after optimization}

Another growth profile of $S$. cerevisiae $\mathrm{HC10}$ was run using the optimized parameter (Figure 4). Exponential phase of $S$. cerevisiae $\mathrm{HC} 10$ can be detected from 0 hour to $15 \mathrm{~h}$ of fermentation time. During this phase, the reproduction and metabolism of yeast is in higher rate. Within $24 \mathrm{~h}$, the number of yeast cell increased up to 1000 -fold. In the basic stages of the growth rate, the first stage of profile growth was lag phase where it occurred during the early fermentation hour time, where the yeast is begin to adapt to new surrounding which show no sign of growth of the yeast. During this phase, oxygen was absorbed by yeast cell to synthesize enzyme and other metabolic for fermentation and growth. From Figure 4, lag phase was not shown because the yeast already acclimated during inoculum time. Deceleration phase was occurred at $18 \mathrm{~h}$ where during this time fermentation and carbon dioxide were produced along with the oxygen depleted. Heat also being produced and bubbling occurred because of the rapid carbon dioxide evolution. The growth rate started to decline at $18 \mathrm{~h}$ to $27 \mathrm{~h}$. This growth occurred was due to the depletion of glucose and cells acclimated to respiratory metabolism. Stationary phase occur at $36 \mathrm{~h}$ to $42 \mathrm{~h}$ when the cells experienced carbon starvation and other nutrients (Stahl et al., 2004).

The highest ethanol production $(5.75 \mathrm{~g} / \mathrm{L})$ was achieved during $15 \mathrm{~h}$ of fermentation (Figure 4). The ethanol concentration increased by $1.65 \mathrm{~g} / \mathrm{L}$ from $4.10 \mathrm{~g} / \mathrm{L}$ after optimization. After $15 \mathrm{~h}$, ethanol concentration started to decrease and the fermentation process stop since glucose become the limiting substrate in the system. Study conducted by Lee and Halim (2014) show that the highest ethanol production achieved after optimization was $6.81 \mathrm{~g} / \mathrm{L}$ which was higher than in this study. This likely due to the total free sugar in the OPFJ study by Lee and Halim (2014) was higher than in this study as mention earlier.

\section{Kinetic study of $S$. cerevisiae $\mathrm{HC10}$}

Based on ANOVA analysis, there were significant difference between $12 \mathrm{~h}$ and $15 \mathrm{~h}$ of fermentation time at optimum condition. Thus, in this kinetic parameter, $15 \mathrm{~h}$ of fermentation time were calculated instead of $12 \mathrm{~h}$ fermentation time. This is because the highest ethanol concentration was achieved at $15 \mathrm{~h}$ under optimum condition and $12 \mathrm{~h}$ at initial condition. From the kinetic 
Table 3: Analysis of Variance.

\begin{tabular}{lcccccc}
\hline Source & Sum of Square & $\mathrm{df}$ & Mean Square & $\mathrm{F}$-Value & $p$-value Prob $>\mathrm{F}$ & \\
\hline Model & 15.98 & 5 & 3.20 & 71.93 & $<0.0001$ & Significant \\
A-agitation & 0.077 & 1 & 0.077 & 1.74 & 0.2284 & Insignificant \\
B-volume of OPFJ & 0.029 & 1 & 0.029 & 0.66 & 0.4441 & Insignificant \\
AB & 0.043 & 1 & 0.043 & 0.96 & 0.3588 & Insignificant \\
$\mathrm{A}^{2}$ & 8.68 & 1 & 8.68 & 195.28 & $<0.0001$ & Significant \\
$\mathrm{B}^{2}$ & 9.22 & 1 & 9.22 & 207.44 & $<0.0001$ & Significant \\
Residual & 0.31 & 7 & 0.044 & & & Insignificant \\
Lack of Fit & 0.23 & 3 & 0.078 & 4.04 & 0.1054 & \\
Pure Error & 0.077 & 4 & 0.019 & & & \\
Cor Total & 16.29 & 12 & & & & \\
\hline
\end{tabular}

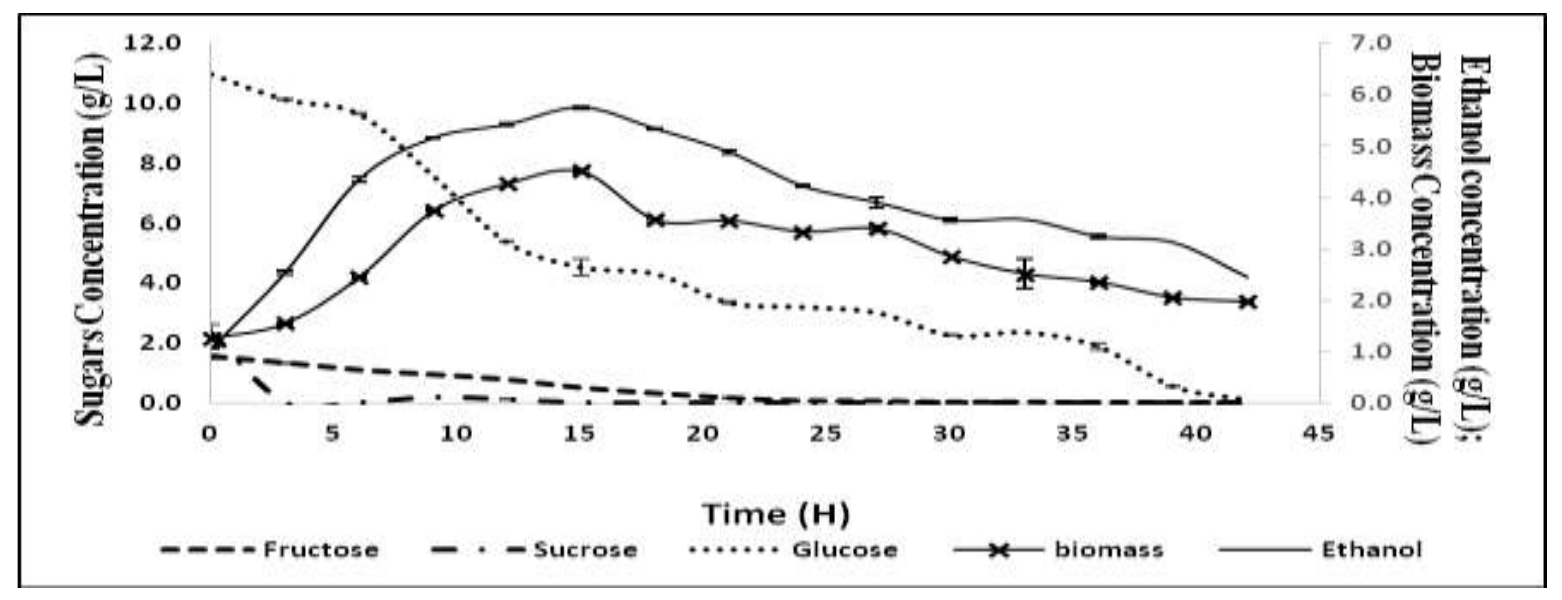

Figure 4: Growth Profile of S. cerevisiae HC10 and sugars utilization pattern after optimization.

values obtained the specific growth rate before and after optimization were $0.11 \mathrm{~h}^{-1}$ and $0.10 \mathrm{~h}^{-1}$, respectively. A study conducted by Paredes-López et al. (1976) shows that Candida utilis that grown on prickly pear in batch culture has a specific growth rate of $0.47 \mathrm{~h}^{-1}$ and recent study by Kartawiria et al. (2015) using $S$. cerevisiae has a specific growth rate of $0.38 \mathrm{~h}^{-1}$ in aerobic condition and $0.17 \mathrm{~h}^{-1}$ in anaerobic condition. Thus, this shown that in cell growth, specific growth rate is depends on environmental condition. At initial and optimum conditions the yeast cells need $6.13 \mathrm{~h}$ and $7.07 \mathrm{~h}$ for the cells to double its population, respectively.

The ethanol yield coefficient at initial fermentation condition was $0.02 \mathrm{~g}$ of ethanol per $\mathrm{g}$ of glucose meanwhile under optimum condition, 3.5 fold increased in ethanol per $\mathrm{g}$ of glucose was obtained compared to initial fermentation condition. A study of ethanol production using batch fermentation by Cheng et al. (2009) showed that the ethanol yield coefficient $(Y \mathrm{p} / \mathrm{s})$ was $0.06 \mathrm{~g}$ of ethanol per $g$ of glucose which was lower than in this study. On the other hand, final and maximum productivity of ethanol at initial condition were $0.34 \mathrm{~g} \mathrm{~L}^{-1} \mathrm{~h}^{-1}$ and $0.04 \mathrm{~g}$ $\mathrm{L}^{-1} \mathrm{~h}^{-1}$ whereas under the optimum condition, the final and maximum productivity of ethanol were $0.30 \mathrm{~g} \mathrm{~L}^{-1} \mathrm{~h}^{-1}$ and $0.05 \mathrm{~g} \mathrm{~L}^{-1} \mathrm{~h}^{-1}$, respectively. The percentage of ethanol yield under optimum condition was higher than at initial condition. This is because cells were grown in suitable environmental conditions which help to maximize the ethanol production.

\section{CONCLUSION}

Agitation rate and volume of oil palm frond juice (OPFJ) have proven can increase the ethanol production in bioreactor. Agitation rate (175 rpm) and volume of oil palm frond juices (40\%) produced $5.01 \mathrm{~g} / \mathrm{L}$ ethanol. Under optimized conditions, the highest ethanol concentration achieved was $5.75 \mathrm{~g} / \mathrm{L}$. On top of that, the ethanol yield $(82 \%)$ was $9 \%$ higher compared to before optimization. This proved that OPFJ is a suitable feedstock for ethanol production.

\section{ACKNOWLEDGMENTS}

The authors would like to thank Universiti Sains Malaysia for providing short term grant (304/PTEKIND/6312113). We would like to acknowledge the contribution from the School of Industrial Technology staffs, especially the laboratory assistant namely Mr. Azmaizan Yaakob and Mrs. Najmah Hamid. They have been very helpful in giving equipment assistance and providing for all my laboratory needs. 


\section{REFERENCES}

Chauhan, S., Nisha and Azmi, W. (2013). Oxygen transfer rate modulates the dextransucrase production by Acetobacter tropicali. Journal of Biochemical \& Microbial Technology 1(1), 1-7.

Che Mohd Hakiman, C. M., Hidayah, A., Mohd Ali, H., Umi Kalsom, M. S. and Yoshihito, S. (2014). Oil palm frond juice as future fermentation substrate: $A$ feasibility study. BioMed Research International 1-8.

Cheng, N. G., Hasan, M. and Kumoro, A.C. (2009). Production of ethanol by fed-batch fermentation. Pertanika Journal of Science and Technology 17(2), 399-408.

Dinie, M., Samsudin, M. and Don, M. M. (2014). Batch fermentation of bioethanol from the residues of Elaeis guineensis: Optimization and kinetics evaluation. Iranica Journal of Energy and Environment 5(1), 1-7.

Galbe, M. and Zacchi, G. (2007). Pre-treatment of lignocellulosic materials for efficient bioethanol production. Advances in Biochemical Engineering/ Biotechnology 108, 41-65.

Ishmayana, S., Learmonth, R. P. and Kennedy, U. J. (2011). Fermentation performance of the yeast Saccharomyces cerevisiae in media with high sugar concentration. Proceedings of the 2nd International Seminar on Chemistry pp. 379-385.

Kartawiria, I. S., Syamsu, K., Noor, E. and Sa'id, G. A. (2015). Sorghum stalk juice pre-treatment method for bioethanol fermentation process. Energy Procedia 65,140-145.

Kosugi, A., Tanaka, R., Magara, K., Murata, Y., Arai, T., Sulaiman, O., Hashim, R., hamid, Z. A. A., Yahya, M. K. A., Yusof, M. N. M., Ibrahim, W. A., and Mori, Y. (2010). Ethanol and lactic acid production using sap squeezed from old oil palm trunks felled for replanting. Journal of Bioscience and Bioengineering 110(3), 322-325.

Lee, C. K. and Halim, F. A. A. (2014). Oil palm fronds juice: A potential feedstock for bioethanol production. International Journal of Scientific and Research Publications 4(12), 520-526.

Maurice, M. L. (2011). Factors effecting ethanol fermentation via simultaneous saccharification and fermentation. B.Sc. Thesis. Worcester Polytechnic Institute, Worcester, United State of America.

Murai, K. and Kondo, R., (2010). Extractable sugar contents of trunks from fruiting and nonfruiting oil palms of different ages. Journal of Wood Science 57(2), 140-148.

Murata, Y., Tanaka, R., Fujimoto, K., Kosugi, A., Arai, T., Togawa, E., Takano, T., Ibrahim, W. A., Elham, P., Sulaiman, O., Hashim, R. and Mori, Y. (2013). Development of sap compressing systems from oil palm trunk. Biomass and Bioenergy 51, 8-16.

Niga, E. (2009). Biotechnological production of bioethanol from different feedstocks: A review. DOCT-US 1(1), 85-90.

Nina Farhana, M. J. (2010). Study on bioethanol production from oil palm trunk (OPT) SAP by using
Saccharomyces cerevisiae Kyokai no.7 (ATCC 26422), B.Sc. Thesis. Universiti Pahang Malaysia, Malaysia.

Nwachukwu, I. N., Ibekwe, V. I., Nwabueze, R. N., Anyanwu, B. N., Ezeji, U., Kalu, I. and Chinakwe, E. (2008). Production of high-ethanol-yielding Saccharomyces cerevisiae of palm wine origin by protoplast fusion. Life Science Journal 5(4), 64-68.

Paredes-López, O., Camargo-Rubio, E. and OrnelasVale, A. (1976). Influence of specific growth rate on biomass yield, productivity, and compostion of Candida utilis in batch and continuous culture. Applied and Environmental Microbiology 31(4), 487-491.

Rodmui, A., Kongkiattikajorn, J. and Dandusitapun, Y., (2008). Optimization of agitation conditions for maximum ethanol production by co-culture. Kasetsart Journal (Natural Science) 42, 285-293.

Rozario, M., (2013). National biomass strategy 2020: new wealth creation for Malaysia's palm oil industry. Agensi Inovasi Malaysia pp.1-32.

Shahirah, M. N. N., Gimbun, J., Pang, S. F., Mohd Zakria, R., Cheng, C. K., Chua, G. K., Farida Asras, M. F. (2014). Influence of nutrient addition on the bioethanol yield from oil palm trunk sap fermented by Saccharomyces cerevisiae. Journal of Industrial and Engineering Chemistry 23, 213-217.

Shankar, U. M. A. (2013). Studies on micro kinetics of diauxic growth. M.Sc. Thesis. Jadavpur University, India.

Stahl, G., Salem, S. N., Chen, L., Zhao, B. and Farabaugh, P. J. (2004). Translational accuracy during exponential, postdiauxic, and stationary growth phases in Saccharomyces cerevisiae. Eukaryotic Cell 3(2), 331-338.

Sun, Y. and Cheng, J., (2002). Hydrolysis of lignocellulosic materials for ethanol production: $A$ review. Bioresource Technology 83(1), 1-11.

Zahari, M., Alimon, A. and Wong, H. (2012). Utilization of oil palm co-products as feeds for livestock in Malaysia. In: Biofuel co-products as livestock feedopportunities and challenges. Makkar, H. P. S. (ed.). Food and Agriculture Organization of the United Nations, Rome. pp.243-302. 